\title{
Identification and characterization of an Endo-glucanase secreted from cellulolytic Escherichia coli ZH-4
}

\author{
Jian Pang ${ }^{1,3}$, Junshu Wang ${ }^{2 *}$, Zhanying Liu' ${ }^{1,3^{*}}$, Qiancheng Zhang ${ }^{1}$ and Qingsheng Qi ${ }^{2}$
}

\begin{abstract}
Background: In the previous study, the cellulolytic Escherichia coli ZH-4 isolated from bovine rumen was found to show extracellular cellulase activity and could degrade cellulose in the culture. The goal of this work was to identify and characterize the secreted cellulase of $E$. coli ZH-4. It will be helpful to re-understand E. coli and extend its application in industry.

Results: A secreted cellulase was confirmed to be endo-glucanase BcsZ which was encoded by bcsZ gene and located in the cellulose synthase operon bcs ABZC in cellulolytic E. coli ZH-4 by western blotting. Characterization of BcsZ indicated that a broad range of $\mathrm{pH}$ and temperature tolerance with optima at $\mathrm{pH} 6.0$ and $50^{\circ} \mathrm{C}$, respectively. The apparent Michaelis-Menten constant $\left(K_{m}\right)$ and maximal reaction rate $\left(V_{\max }\right)$ for BcsZ were $8.86 \mathrm{mg} / \mathrm{mL}$ and $0.3 \mu \mathrm{M} /$ min.mg, respectively. Enzyme activity of $\mathrm{Bcs} Z$ was enhanced by $\mathrm{Mg}^{2+}$ and inhibited by $\mathrm{Zn}^{2+}, \mathrm{Cu}^{2+}$ and $\mathrm{Fe}^{3+}$. BcsZ could hydrolyze carboxymethylcellulose (CMC) to produce cello-oligosaccharides, cellotriose, cellobiose and glucose.

Conclusions: It is confirmed that extracellular cellulolytic capability of E. coli ZH-4 was attributed to BcsZ, which explained why E. coli ZH-4 can grow on cellulose. The endo-glucanase BcsZ from E. coli-ZH4 has some new characteristics which will extend the understanding of endo-glucanase. Analysis of the secretion characteristics of BcsZ provided a great reference for applying $E$. coli in multiple industrial fields.
\end{abstract}

Keywords: Cellulolytic Escherichia coli ZH-4, Secretory endo-glucanase, BcsZ, Enzyme characterization

\section{Background}

Cellulose biomass is the most abundant carbohydrate on the earth. It can be hydrolyzed to reducing sugars for production of biofuels and chemicals, and thus has a great economic and commercial potential [1]. Cellulose as the main component of plant cell wall consists of linear long chains of $\beta-1,4$ glucose units. Hydrolyzing cellulose by cellulase is ideal and promising for its utilization in environmentally friendly and high efficiency manner [2]. However, the cooperative action of three kinds of cellulolytic enzymes (endo-glucanase, exo-glucanase, and $\beta$-glucosidase) is essential in hydrolysis of cellulose to glucose [3]. Among three kinds of cellulolytic enzymes, endoglucanases plays an important role in

\footnotetext{
*Correspondence: wangjunshusdu@163.com; zyliu1979@163.com

${ }^{2}$ State Key Laboratory of Microbial Technology, Shandong University, Qingdao 266237, China

'School of Chemical Engineering, Inner Mongolia University of Technology, Hohhot 010051, Inner Mongolia, China

Full list of author information is available at the end of the article
}

the process of cellulose hydrolysis because it hydrolyzes the glycosidic bond randomly and shorten the cellulose chains in the initial stage of cellulose breakdown [4]. Cellulase is produced by various cellulolytic bacteria and fungi which have been isolated from different environment [5]. Isolating cellulolytic microorganisms from various environment and characterizating their cellulase are crucial for understanding the evolution mechanism of cellulolytic microorganisms and the hydrolysis mechanism of cellulase, which will promote their application in industry. In recent years, cellulase from bacteria was focused again because the glycoside hydrolases of cellulolytic bacteria are very diverse [6].

The previous study revealed that a cellulase (Cel-CD) from Bacillus sp. can be secreted into culture medium when Cel-CD was overexpressed in E.coli with or without its signal peptide, which indicated that $E$. coli has the capacity of secreting cellulase [7]. In addition, cellulolytic E. coli will be got when expressed this cellulase in

(c) The Author(s). 2019 Open Access This article is distributed under the terms of the Creative Commons Attribution 4.0 International License (http://creativecommons.org/licenses/by/4.0/), which permits unrestricted use, distribution, and 
E. coli, and the E. coli has a potential application to produce enzymes and chemicals directly from lignocellulose biomass [8].

In our previous study, a cellulolytic E. coli $\mathrm{ZH}-4$ was isolated from the rumen [9]. E. coli $\mathrm{ZH}-4$ is capable of converting corn straw to ethanol and hydrogen anaerobically. Extracellular endo-glucanase and $\beta$-glucosidase activity were detected. The results indicated that such enzymes were expressed and secreted in cellulolytic $E$. coli $\mathrm{ZH}-4$. Genome sequence analysis of $E$. coli $\mathrm{ZH}-4$ revealed an endoglucanase gene (Genbank accession number KY965823) encoding a BcsZ homolog.

From another point of view, cellulose is a major structural component in bacteria, which provides cell-surface and cell-cell interaction in various of biofilm models, and protects cells against chlorine treatment [10-12]. The previous study showed that inactivation of BcsZ altered the cellulose-associated phenotypes in Salmonella enterica serovar Typhimurium, such as rdar biofilm morphotype, cell clumping, biofilm formation, pellicle formation and flagella-dependent motility [10]. The hydrolase activity of BcsZ is hypothesized to mediate alignment of each $\beta-1,4$ -glucan for proper cellulose microfibril formation [13]. $B c s Z$ is a conserved component of the cellulose synthase operon $b c s A B C Z$, which encodes the cellulose synthase $\mathrm{Bcs} A \mathrm{~B}$ and the outer membrane porin for cellulose translocation and secretion [10, 14]. BcsZ belongs to Glycoside Hydrolase family 8 with endo-1,4-D-glucanase activity. BcsZ hydrolyzes glycosidic bonds by a pair of acidic residues inverting the anomeric configuration at the new reducing end [15]. The crystal structure analysis of BcsZ from $E$. coli showed an $(\alpha / \alpha){ }_{6}$-barrel fold. BcsZ binds 4 glucan moieties of cellopentaose via highly conserved residues exclusively on the non-reducing side of its catalytic center [13]. However, whether BcsZ is responsible for cellulolytic ability of $E$. coli $\mathrm{ZH}-4$ is uncertain. Little is known about the characteristic of BcsZ-ZH-4. Enzymatic hydrolysate of BcsZ-ZH-4 from cellulose is unknow.

In this study, the cellulolytic ability of $E$. coli $\mathrm{ZH}-4$ was verified from BcsZ. The endoglucanase was assessed through transcription, expression and secretion. BcsZ from E. coli $\mathrm{ZH}-4$ was functionally expressed in $E$. coli BL21 (DE3), and the recombinant protein was purified and characterized.

\section{Results}

Identification and verification of secreted cellulase in cellulolytic E. coli $\mathrm{ZH}-4$

The mature protein in the culture medium was analyzed through western blotting to identify the extracellular endoglucanase in $\mathrm{ZH}-4$. The coding gene was located on the operon of $b c s A B Z C$. Meanwhile, the extracellular protein was verified by western blotting using BcsZ antiserum (Fig. 1). The transcription level of $b c s Z$ in cellulolytic E. coli ZH-4 was also found to be $2.6 \pm 0.25$ and $6.0 \pm 0.26$ fold higher than that of E. coli MG1655 under aerobic and anaerobic condition respectively (Fig. 2).

A signal peptide sequence of 1-21 amino acid residues was found in E. coli $\mathrm{ZH}-4$ by the analysis of the protein sequence. In compared to $E$. coli MG1655, there were two amino acids difference in BcsZ of E. coli ZH-4: Ser63 to Phe (Ser-Phe) and Ala71to Val (Ala-Val). The $b c s Z$ located in the downstream of $b c s B$ and was supposed under the control of the $b c s B$ promoter. DNAbinding transcriptional dual regulator FNR (Fnr) regulates $b c s B Z$ operon expression under anaerobiosis, and the putative FNR-binding site was identified in upstream of this operon. Genetic analysis of the operon indicated that there was no difference with that of MG1655 in the regulation and transcription region.

\section{Expression and purification of endo-glucanase BcsZ}

The bcsZ gene amplified from E. coli $\mathrm{ZH}-4$ was cloned in pET-28a vector, and then overexpressed in E. coli BL21 (DE3). BcsZ was detected in culture medium (Fig. 3a, line 1) with the recombinant cell by Sodium dodecyl sulfate polyacrylamide gel

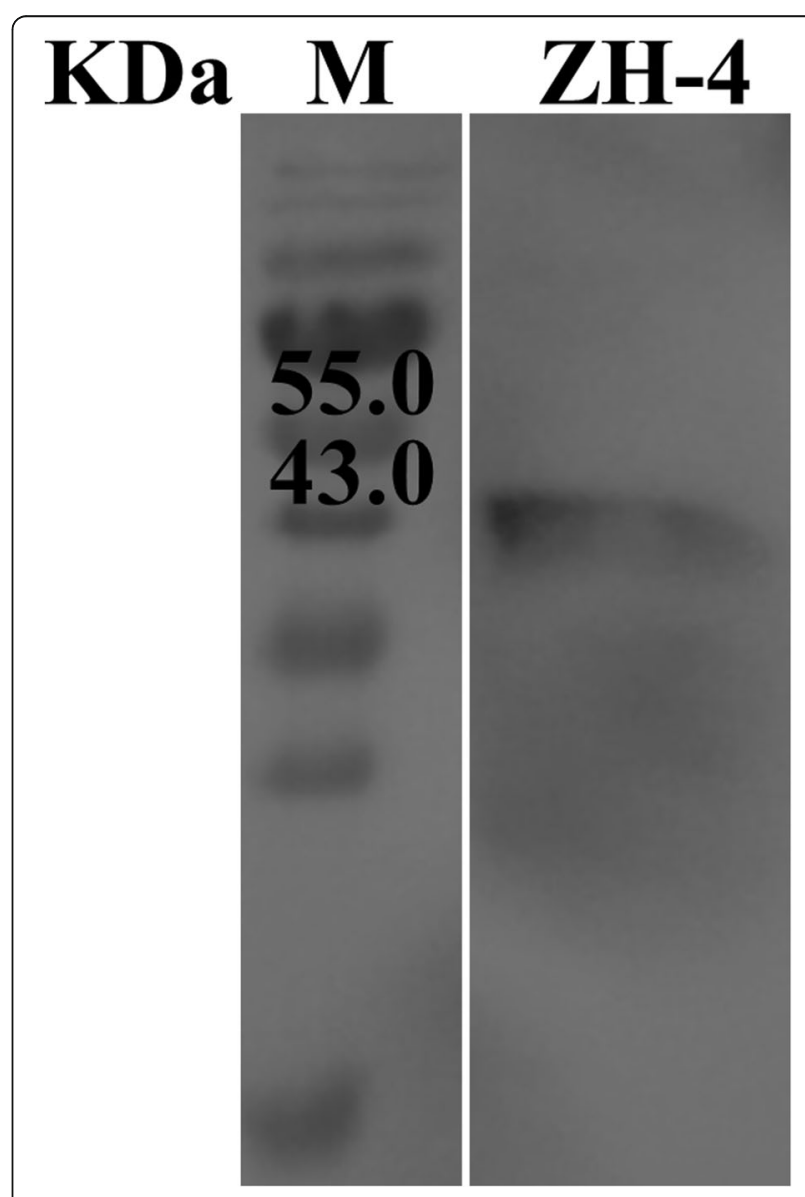

Fig. 1 Western Blotting analysis of BcsZ in culture medium 


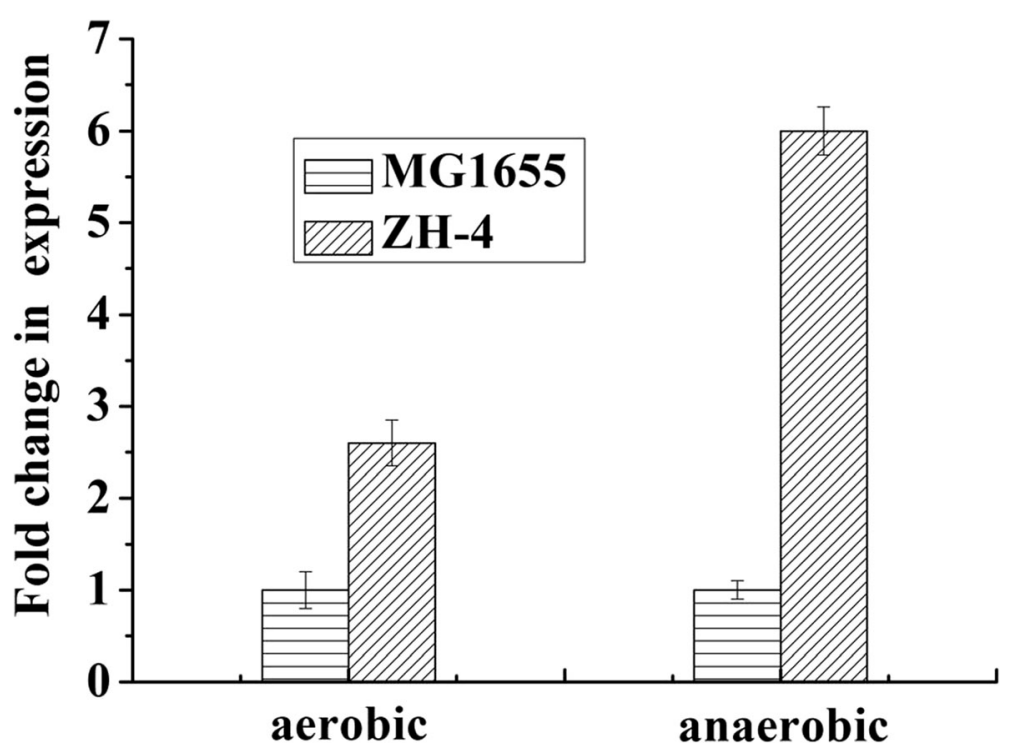

Fig. 2 The fold change in gene expression of bcsZ in E. coli ZH-4 and MG1655

electrophoresis (SDS-PAGE). The result indicated that endo-glucanase, BcsZ, can be secreted to the outside of cell. The crude protein of BcsZ was purified, and the purified protein appeared as a single protein band on SDS-PAGE gel with a molecular mass of $41.7 \mathrm{KD}$, which was consistent with prediction (Fig. 3a, line 3). The E. coli BL21 (DE3) carrying the pET-28a vector (empty) was used as control (Fig. 3b).

\section{Characterization of the endo-glucanase BcsZ}

The optimal temperature and $\mathrm{pH}$ of purified BcsZ were determined. As shown in Fig. 4a, the optimum temperature was $50^{\circ} \mathrm{C}$. With the rising of the temperature, the enzyme activity began to decrease, but retained over $70 \%$ at the temperature of till $65^{\circ} \mathrm{C}$. The enzyme activity sharply decreased when the temperature is over $65^{\circ} \mathrm{C}$, and was remained by $40 \%$ when the temperature was $80^{\circ} \mathrm{C}$. From Fig. 4b, the BcsZ displayed

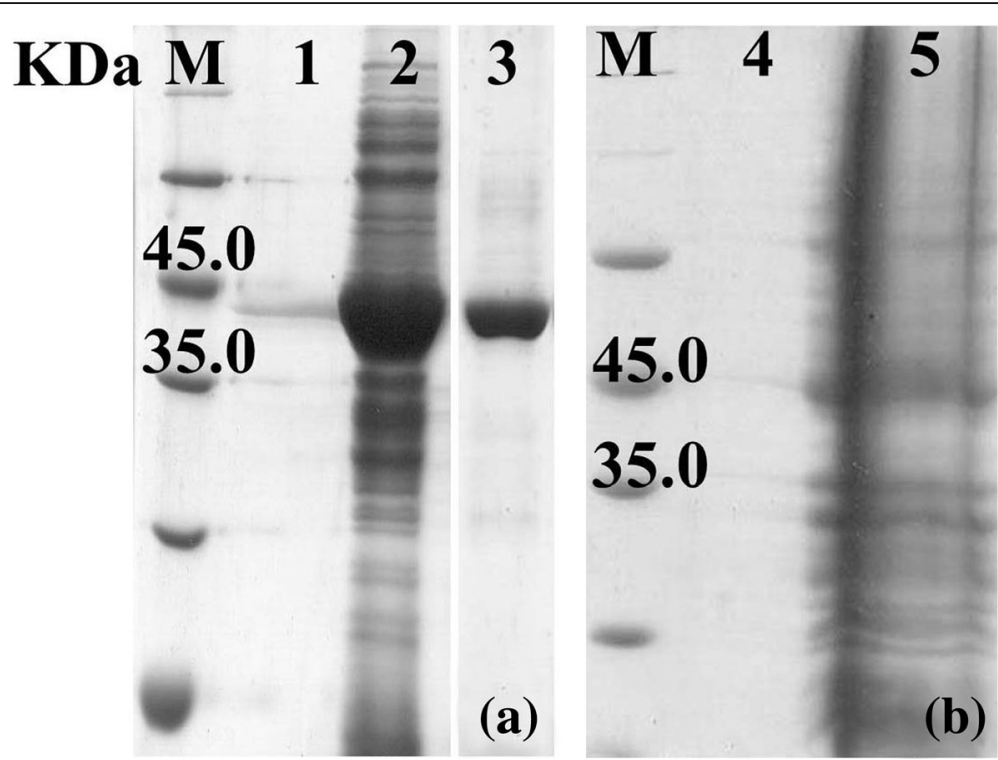

Fig. 3 SDS-PAGE analysis of recombinant BcsZ protein stained with coomassie blue (a). M: Protein molecular weight marker; Lane 1: BcsZ in culture medium; Lane 2: BcsZ in cells; Line 3: The purified BcsZ. The E. coli BL21 (DE3) carrying the empty plasmid was used as control (b). Line 4: culture medium; Line 5 : cells 

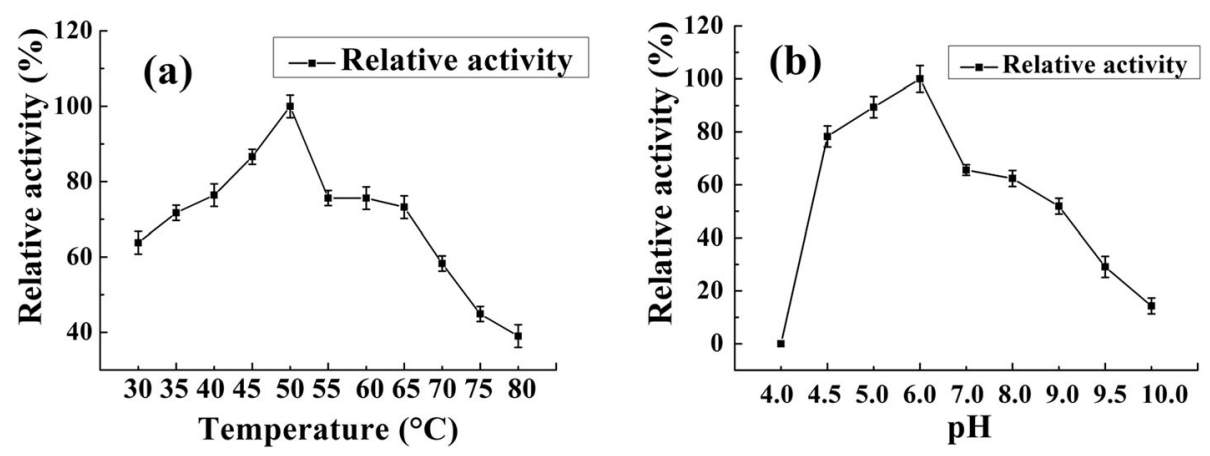

Fig. 4 The optimum temperature (a) and pH (b) of BcsZ

optimal activity at pH 6.0. It had relatively high enzyme activity at the broad $\mathrm{pH}$ range of 4.5-9.0. BcsZ was sensitive to the acidic condition. It remained about $80 \%$ activity when $\mathrm{pH}$ at 4.5 , and enzyme activity was not detected when the $\mathrm{pH}$ was 4.0. The BcsZ protein has a tolerance to alkali solution because it retained over 15\% of the maximum enzyme activity when the $\mathrm{pH}$ was 10.0 .

The thermal stability result was shown in Fig. 5, and showed BcsZ displayed high thermal stability at $50^{\circ} \mathrm{C}$ and $60{ }^{\circ} \mathrm{C}$ with about 90 and $70 \%$ of its enzyme activity remained, respectively. The enzyme activity wasn't detected at $70^{\circ} \mathrm{C}$ after $0.5 \mathrm{~h}$ incubation.

The substrate specificity results were shown in Table 1. As shown in Table 1, BcsZ displayed enzyme activity with CMC, RAC and glucan (data not shown) as substrate. The enzyme showed a weak catalytic activity on Avicel, xylan, cellobiose, laminarin and chitin. The $K_{m}$ value of BcsZ for CMC as substrate was
$8.86 \mathrm{mg} / \mathrm{mL}$, and the calculated $\mathrm{V}_{\max }$ was $0.3 \mu \mathrm{M} /$ $\mathrm{min} \cdot \mathrm{mg}$.

\section{Effect of metal ion on BcsZ activity}

The effect of metal ions on the enzyme activity of BcsZ was examined (Fig. 6). The enzyme activity was improved $165 \%$ by $\mathrm{Mg}^{2+}$. $\mathrm{Fe}^{3+}$ inhibited BcsZ, and $74 \%$ enzyme activity was lost with10 $\mathrm{mM} \mathrm{Fe}{ }^{3+} \cdot \mathrm{Zn}^{2+}$ also inhibited the enzyme of BcsZ, and there was $66 \%$ of enzyme activity was left with $10 \mathrm{mM} \mathrm{Zn}^{2+}$. The enzyme was strongly inhibited by $\mathrm{Cu}^{2+}$, there is no enzyme activity detected when $\mathrm{Cu}^{2+}$ concentration reached $5 \mathrm{mM}$ in the reaction system.

\section{Analysis of hydrolysis products by TLC}

The hydrolysis products of CMC and RAC were analyzed by TLC. As shown in Fig. 7, glucose was released when BcsZ hydrolyzed RAC (G9). The hydrolysis

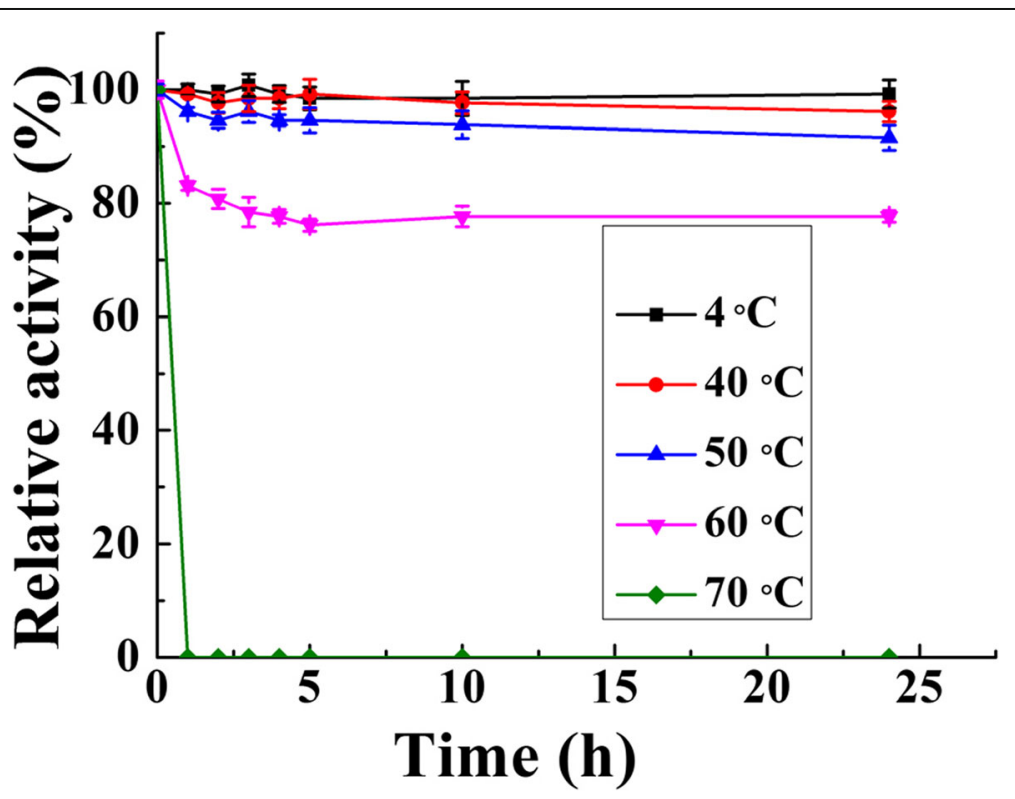

Fig. 5 The thermostability of BcsZ 
Table 1 Substrate specificity of BcsZ

\begin{tabular}{ll}
\hline Substrate & Specific activity (IU/mg) \\
\hline CMC & $0.84 \pm 0.05$ \\
RAC & $0.52 \pm 0.08$ \\
Avicel & $<0.01$ \\
xylan & $<0.01$ \\
cellobiose & $<0.01$ \\
laminarin & $<0.01$ \\
chitin & $<0.01$ \\
\hline
\end{tabular}

products were glucose, a small amount of cellobiose and cellotriose, and unknown cello oligosaccharides from CMC (G7) as substrate.

\section{Discussion}

In our previous study, a cellulolytic E. coli $\mathrm{ZH}-4$ was isolated from bovine rumen, this strain could produce extracellular cellulases. In this study, secretion of BcsZ to culture medium was confirmed by western blotting (Fig. 1). These results explained the reason $\mathrm{ZH}-4$ formed a clear zone in anaerobic Hungate roll tubes (containing cellulose and Congo red) [9]. While E. coli strain MG1655 and W3110 didn't generate the above phenotype at the same condition. Secretion of cellulase (BcsZ) and its contribution to the cellulolytic capacity of $E$. coli $\mathrm{ZH}-4$ were confirmed, which were consistent with our previous supposition and the published [9]. The previous studies showed overexpression of BcsZ in $E$. coli leads to its secretion to extracellular space and formation of clear zone on congo red plates [16, 17]. Further analysis confirmed that the transcription level of bcs $\mathrm{Z}$ in $\mathrm{ZH}-4$ was higher than that of MG1655, especially under anaerobic condition. The increased transcription level of $b c s Z$ is critical to the cellulolytic activity of E. coli $\mathrm{ZH}-4$. Sequence analysis showed that the promoter, Fnr and FNR-binding site of $b c s Z$ in $E$. coli $\mathrm{ZH}-4$ is consistent with MG1655 and W3110. The genome of E. coli ZH-4 (5.3 Mb) is larger than E. coli MG1655 (4.6 Mb). It is supposed that some regulatory factors and elements regulate $b c s Z$ transcription and expression in E. coli $\mathrm{ZH}-4$. This may lead to the increased transcription level of $b c s Z$ in $E$. coli $\mathrm{ZH}-4$. Further elevated transcription level investigation of $b c s Z$ may reveal the difference in BcsZ secretion between $E$. coli $\mathrm{ZH}-4$ and MG1655.

The endo-glucanase BcsZ had the broad pH range and strong alkali tolerance. These characteristics of BcsZ might be affected by the rumen habitat and consistent with the previous reports. For instance, Gong et al. cloned and identified some novel hydrolase genes from a dairy cow rumen. The purified recombinant enzyme displayed optimal activity at $\mathrm{pH} 6.0$ and $50{ }^{\circ} \mathrm{C}$. It was stable over a broad $\mathrm{pH}$ range, from pH 4.0 to 10.0 [18]. Chang et al. reported an endoglucanase from yak rumen microorganisms and the optimal conditions for enzyme activity were $50{ }^{\circ} \mathrm{C}$ and $\mathrm{pH} 5.0$ [19]. BcsZ is mesophilic enzyme which is in line with the other endoglucanse in some microorganisms such as Bacillus sp. HSH-810 [20], Komagataeibacter xylinus [21].

Metal ions significantly affected the enzymatic catalytic activity based on the above results. Endoglucanase of GH8 family has two conserved glutamate residues at the active site and the cellulase activity might be restrained when metal ions is bound to the radical of these residuals [22]. $\mathrm{Mg}^{2+}$ might enhance cellulase activity through altering the dimensional structure of BcsZ or stabilizing the enzyme structural conformation. $\mathrm{Co}^{2+}, \mathrm{Mn}^{2+}$, and

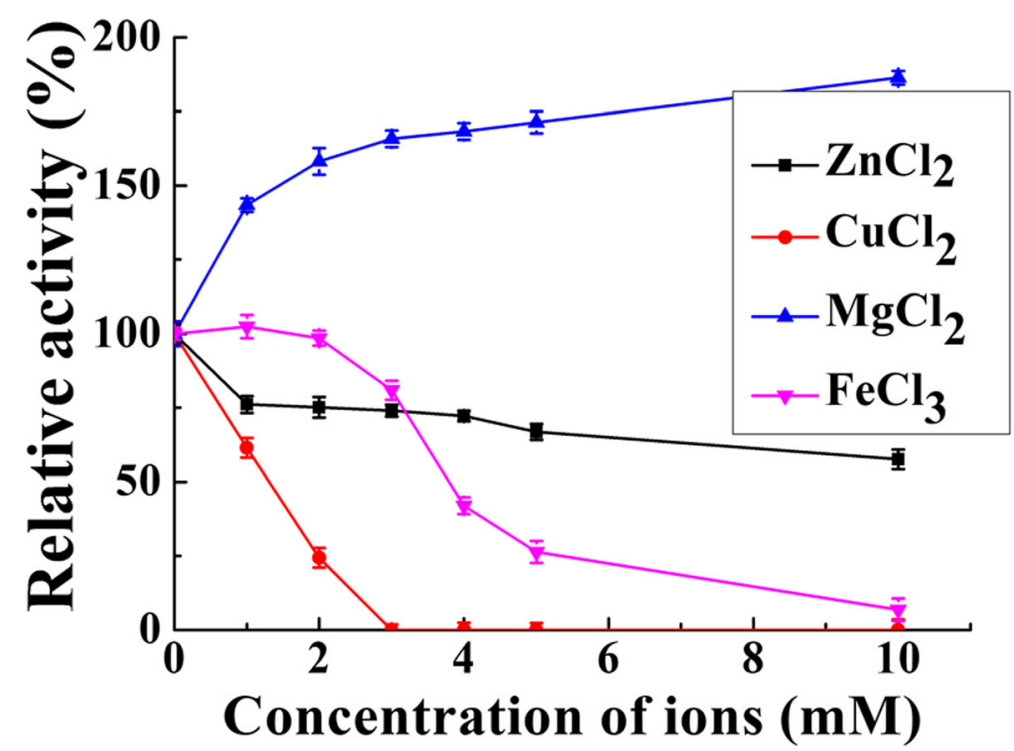

Fig. 6 The effect of metal ions on the activity of BcsZ 


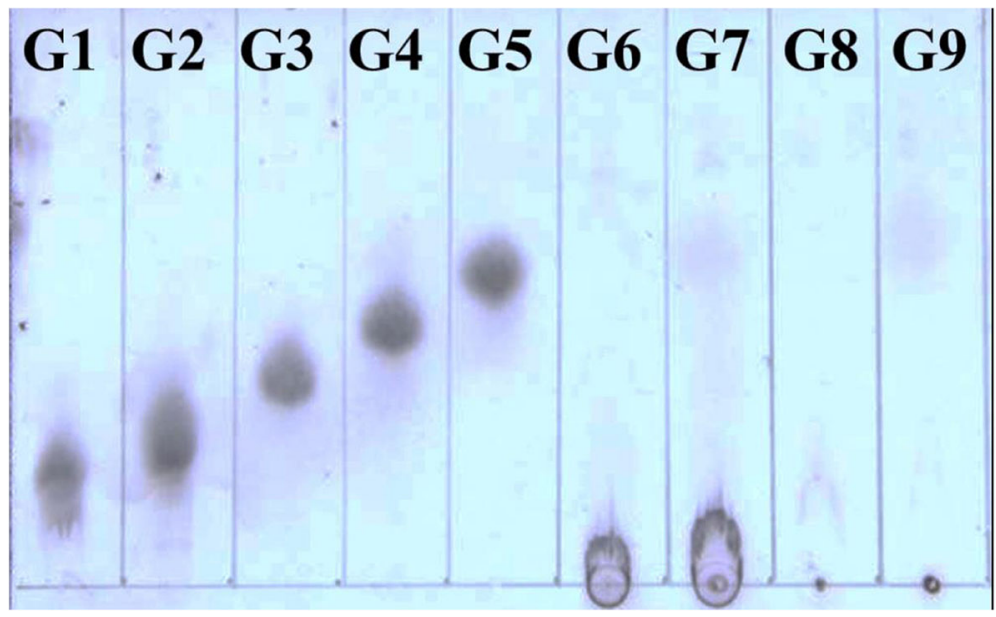

Fig. 7 TLC analysis of hydrolysates of CMC and RAC catalyzed by BcsZ. Standards of Cellopentose (G1), Cellotetraose (G2), Cellotriose (G3), Cellobiose (G4) and Glucose (G5); CMC incubated with inactivated BcsZ as the control (G6), CMC incubated with BcsZ (G7); RAC incubated with inactivated BcsZ as the control (G8), RAC incubated with BcsZ (G9)

$\mathrm{Fe}^{2+}$ enhanced the enzyme activity of GHF9 endoglucanase from Reticulitermes speratus, but $\mathrm{Pb}^{2+}$ and $\mathrm{Cu}^{2+}$ inhibited its enzyme activity [23]. Meleiro et al cloned and overexpressed an endoglucanase (Egst) from Scytalidium thermophilum that showed high catalytic activity at harsh condition. $\mathrm{NH}^{4+}, \mathrm{Na}^{+}, \mathrm{K}^{+}, \mathrm{Ba}^{2}+, \mathrm{Ca}^{2+}$ and $\mathrm{Mg}^{2+}$ had little effect on Egst. $\mathrm{Cu}^{2+}$ presented a slight inhibitory effect and $\mathrm{Hg}^{2+}$ had a strong inhibitory effect on Egst [24].

BcsZ could hydrolyze CMC-Na, RAC and glucan. BcsZ had a higher affinity for CMC than Thcel9A $(12.02 \mathrm{mg} / \mathrm{mL})$ from Thermobifida halotolerans YIM $90462 \mathrm{~T}$ [25], the purified endoglucanase $(21.01 \mathrm{mg} / \mathrm{mL})$ from Aspergillus niger $B 03$ [26] and C67-1 (37 mg/mL) from metagenomes of buffalo rumens [27]. It had a weaker affinity for CMC than the endoglucanase from Bacillus $s p$. $(0.8 \mathrm{mg} / \mathrm{mL})$ [28]. The $\mathrm{V}_{\max }$ value $(0.3 \mu \mathrm{M} / \mathrm{min} \cdot \mathrm{mg})$ of $\mathrm{BcsZ}$ was lower than Cell-1 $(0.84 \mu \mathrm{mol} / \mathrm{min} \cdot \mathrm{mg})$ [29] and an endoglucanse $(1000 \mu \mathrm{M} /$ min) [28]. The $V_{\max }$ value of BcsZ was low indicating this enzyme had a weak catalytic efficiency for CMC.

The BcsZ from E. coli $\mathrm{ZH}-4$ could be classified as an endo- $\beta-1,4$ glucanase according to its product pattern. Some other endo- $\beta-1,4$ glucanases also have the above properties. An endoglucanase was expressed and characterized from Serratia proteamaculans CDBB-1961 by Cano-Ramírez, and then was applied to hydrolyze CMC to glucose and cello oligosaccharides [30]. The endo- $\beta-1,4$ glucanase (E4-90) from Termomonospora fusca hydrolyzed CMC to produce cellobiose, cellotriose, cellotetraose and glucose [31]. As the previous study, a purified $\beta-1,4$ endoglucanase (LbGH5) could hydrolyze $\mathrm{CMC}$ and phosphoric acid swollen cellulose (PASC) with the enzymatic hydrolysate including cellobiose, cellotriose, cellotetraose and a small amount of cellopentaose and glucose [32]. In contrast, a thermophilic endo-1, 4- $\beta$ glucanase from Sulfolobus shibatae hydrolyzed cellotetraose and cellopentose not cellobiose or cellotriose. The products of CMC hydrolysis were cellobiose, cellotriose, cellotetraose and cellopentose [33]. Cellobiose and cellotriose was produced from PASC and Avicel respectively, and cellobiose, cellotriose and cellotetraose were produced from $\mathrm{CMC}$ with Endo-glucanase EG5C-1 [34]. The release of significant amount of glucose also explained why E.coli $\mathrm{ZH}-4$ can grow on cellulose. Our experiments also showed that expression of BcsZ in E.coli BL21 resulted in the growth of E.coli BL21 on cellulose. These identification and characterization of BcsZ may improve understanding the adaptation of E. coli to different environment.

\section{Conclusions}

BcsZ was shown to be responsible for extracellular endoglucanase activity and cellulolytic capability of E. coli ZH-4. Expression, purification and characterization of the endoglucanase BcsZ showed that it was thermotolerant and $\mathrm{pH}$ tolerant. This enzyme could hydrolyze CMC to produce glucose, cellobiose, cellotriose and unknown cello oligosaccharides, which explained why E. coli $\mathrm{ZH}-4$ can grow on cellulose.

\section{Methods}

\section{Bacterial strains and culture conditions}

The cellulolytic E. coli $\mathrm{ZH}-4$ was isolated from the bovine rumen by our laboratory and it was preserved in China General Microbiological Culture Collection Center (CGMCC) (Preservation No. 12427). E. coli DH5 $\alpha$ was used for plasmid amplification, and E. coli BL21 (DE3) was used as the host for recombinant protein expression with pET28a as vector. E. coli strains were routinely cultured in Luria-Bertani (LB) medium at $37^{\circ} \mathrm{C}$ with shaking at $220 \mathrm{rpm}$. Kanamycin was added when needed at a final concentration of $50 \mu \mathrm{g} / \mathrm{mL}$. 


\section{Quantitative RT-PCR analysis}

Total RNA was extracted using the RNAprep pure Cell/ Bacteria Kit (TIANGEN) following manufacturer's instruction. The concentration and quality of RNA was measured using the Nano-Drop spectrophotometry (NanoDrop Technologies, Wilmington, DE, USA). The cDNA was synthesized according to the First Stand cDNA Synthesis Kit (TOYOBO) following the manufacturer's protocol. The primers were displayed in Table 2. The PCR reaction included $12.5 \mathrm{uL}$ SYBR Green Realtime PCR Master Mix (TOYOBO), 2.5 uL diluted cDNA $(500 \mathrm{mM})$ reaction mixture, $1 \mathrm{uL}$ each forward and re-

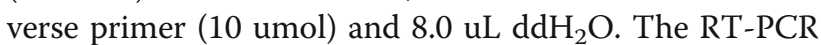
assays were performed on a 7900HT Fast Real-Time PCR System (Applied Biosystems, Carlsbad, California, USA). The relative gene expression calculated by the equation of $2^{(-\Delta \Delta \mathrm{Ct})}$ method (Applied Biosystems Research Bulletin No. 2 P/N 4303859).

\section{Western blot analysis}

Western blotting was performed as described by Sambrook [35]. Proteins separated by SDS-PAGE were transferred onto polyvinylidene difluoride (PVDF) membranes (Millipore, Billerica, MA, USA) using the Bio-Rad semi-dry apparatus. The blots were incubated with primary anti-BcsZ serum in 1 : 2000 dilution in $2 \%$ (wt/vol) skimmed milk for $1 \mathrm{~h}$ with agitation at room temperature followed by washes with PBST buffer (PBS buffer with 1\% Tween) for 3 times. The secondary antibody with horseradish peroxidase (HRP) conjugated goat anti-rabbit (1:2000 dilution) was performed as above. Blots were developed with the ECL Plus Kit (Thermo Scientific, US) following the manufacturer's directions. The in-gel identification of secreted protein by mass spectrometry analysis was performed by Shenzhen BGI gene co., LTD.

\section{Sequence analysis}

bcs $Z$ gene sequences from E. coli $\mathrm{ZH}-4$ and $E$. coli MG1655 was compared using the BLASTN program (https://blast.ncbi.nlm.nih.gov/Blast.cgi).

\section{Plasmid construction}

To overexpress BcsZ, $b s c Z$ gene was amplified from $E$. coli ZH-4 using primers BcsZ-F (5' - CGCGGATCCG GGTGTGAATTTGCGCATTCCT-3') and BcsZ-R (5'CATGCCATGGGCAATGTGTTGCGTAGTGGAAT-

$\left.3{ }^{\prime}\right)$. The PCR products were then digested and cloned

Table 2 The primers of qRT-PCR

\begin{tabular}{ll}
\hline Primers & Sequences $\left(5^{\prime}-3^{\prime}\right)$ \\
\hline bcsZ-F & GAGAACAGTAAGTGGGAAGTGC \\
bcsZ-R & AACGCTGCTCTTTCCACAAACG \\
$16 S$ rRNA-F & GCTCAACCTGGGAACTGC \\
$16 S$ rRNA-R & CCACGCTTCGCACCTGA \\
\hline
\end{tabular}

into BamHI and NcoI sites of pET-28a plasmid. His-tag was located in C-terminus of bcsZ. The constructed expression vector pET-28a-BcsZ was verified by DNA sequencing.

\section{Protein expression and purification}

Overnight culture of E. coli BL21 (DE3) harboring plasmid pET-28a-BcsZ was inoculated to fresh LB medium supplemented with $50 \mu \mathrm{g} / \mathrm{mL}$ kanamycin in 1:100 dilution and cultured at $37^{\circ} \mathrm{C}$ with shaking. The E. coli BL21 (DE3) carrying the empty plasmid was used as control. To induce $b s c Z$ gene expression, isopropyl- $\beta$ - d-thiogalactoside (IPTG) was added to the culture at a final concentration of $0.25 \mathrm{mM}$ when the optical density at 600 $\mathrm{nm}$ reached 0.4 0.6. Cells were harvested by centrifugation $(8000 \times \mathrm{g}, 10 \mathrm{~min})$ after $24 \mathrm{~h}$ cultivation at $25^{\circ} \mathrm{C}$ with shaking at $220 \mathrm{rpm}$. The resulting cells were suspended in $10 \mathrm{mM}$ phosphate buffer saline (PBS) with PMSF and DNase I. The cells were lysed using JNBIO JN-3000 PLUS high-pressure cell press. Then, the crude cell lysate was prepared by centrifugation $(12,000 \times \mathrm{g}, 30 \mathrm{~min})$ to remove the cell debris.

The BcsZ was further purified by affinity chromatography using HisPur Cobalt Resin (Thermo Fisher Scientific Inc) according to the manufacturers' instruction. The purity and homogeneity of the purified enzyme was detected by SDS-PAGE.

\section{Enzyme assay and protein determination}

The enzyme activity of BcsZ was determined by the standard DNS method [36]. The mixture of $1.5 \mathrm{~mL} 1 \%(\mathrm{w} / \mathrm{v})$ CMC solubilized in $50 \mathrm{mM}$ phosphate buffer $(\mathrm{pH} 6.0)$ and $0.5 \mathrm{~mL}$ purified BcsZ was incubated at $50^{\circ} \mathrm{C}$ for $30 \mathrm{~min}$. The the reaction was stopped by the addition of $3 \mathrm{~mL}$ of DNS. The release of reducing sugars was determined by the absorbance at $540 \mathrm{~nm}$. One unit of activity is defined as the amount of enzyme that released $1 \mu \mathrm{mol}$ of reducing sugars $/ \mathrm{min}$ from CMC. Protein concentration was measured by Bradford method using bovine serum albumin as standard [37].

\section{Basic biochemical character of BcsZ}

The optimum $\mathrm{pH}$ was determined by measuring BcsZ activity in different buffers $(50 \mathrm{mM})$ of $\mathrm{pH}$ ranging from 4.0 to 10.0: citric acid buffer for $\mathrm{pH}$ 4.0-6.0; phosphate buffer for $\mathrm{pH}$ 6.0-8.0; Glycine-NaOH buffer for $\mathrm{pH}$ 8.5-10.0. The optimum temperature was identified by incubating the enzyme in phosphate buffer ( $\mathrm{pH}$ 6.0) at different temperatures $\left(30-80^{\circ} \mathrm{C}\right)$. For thermostability determination of BcsZ, it was incubated at different temperatures $4,40,50,60$ and $70^{\circ} \mathrm{C}$ for $0.5,1,2,3,4,5,10$ and $24 \mathrm{~h}$. The residual endoglucanase activity was determined, respectively. The influence of metal ions on enzyme activity of BcsZ was measured in presence of tested metal ions at indicated concentration. All enzyme activity was measured as previously described. The highest 
enzymatic activity was used as benchmark of $100 \%$ activity when calculating relative activity.

\section{Kinetic constants}

The kinetic parameter values Michaelis-Menten constants $\left(\mathrm{K}_{\mathrm{m}}\right)$ and maximum velocity $\left(\mathrm{V}_{\max }\right)$ were determined to calculate the $K_{m}$ value of BcsZ on CMC hydrolysis according to double-reciprocal LineweaverBurk plots (Eq. 1). The activity assay was performed with $\mathrm{CMC}$ at different concentrations at $\mathrm{pH} 6.0$ and $50{ }^{\circ} \mathrm{C}$ for $10 \mathrm{~min}$.

$$
\frac{1}{V}=\frac{K_{m}}{V_{\max }} \frac{1}{[S]}+\frac{1}{V_{\max }}
$$

\section{Substrate specificity}

The hydrolytic ability of BcsZ on $1 \%$ (w/v) of various substrates were determined by DNS method under optimal conditions. The substrate included Avicel, $\mathrm{CMC}-\mathrm{Na}$, regenerated amorphous cellulose (RAC), xylan, cellobiose, laminarin and chitin.

\section{Thin layer chromatographic (TLC)}

The products were analyzed by Thin Layer Chromatographic (TLC) as previously described when BcsZ hydrolyzed CMC and RAC [38].

\section{Statistical analysis}

All experiments were conducted in triplicate and the data were presented as mean values \pm standard deviation.

\begin{abstract}
Abbreviations
CGMCC: China General Microbiological Culture Collection Center; CMC: carboxymethylcellulose; DNS: dinitrosalicylic; GH: Glycoside hydrolase; HRP: horseradish peroxidase; IPTG: isopropyl- $\beta$ - d-thiogalactoside; LB: LuriaBertani; PBS: phosphate buffer saline; PVDF: polyvinylidene difluoride; RAC: Regenerated amorphous cellulose; SDS-PAGE: Sodium dodecyl sulfatepolyacrylamide gel electrophoresis; TLC: Thin layer chromatographic
\end{abstract}

\section{Acknowledgments}

Not applicable.

\section{Authors' contributions}

JP did the experimental work and wrote the draft manuscript. JSW revised and designed the draft manuscript. ZYL participated in the design of the study. QCZ took part in checking the results. QSQ participated in the design of the study and commented on the manuscript. All authors read and approved the final manuscript.

\section{Funding}

This work was supported by the National Natural Science Foundation of China [Grant number 31730003]; the National Natural Science Foundation of China (NSFC) [Grant number 61361016]; the Foundation of Talent Development of Inner Mongolia and the "Prairie talent" project of Inner Mongolia [Grant number CYYC20130034]; the National Natural Science Foundation of Inner Mongolia [Grant number 2018MS02019]; the Science and Technology Planning Project of Inner Mongolia; and the Graduate student education innovation planning project of Inner Mongolia [Grant number B2018111925]. These funding bodies had no role in the design of the study and collection, analysis, and interpretation of data and in writing the manuscript.

\section{Availability of data and materials}

The datasets generated and/or analyzed during the current study are available on the GenBank repository, https://www.ncbi.nlm.nih.gov/nuccore/ KY965823. The GenBank accession number for the nucleotide sequence of bcs $Z$ referred to in the text is KY965823. Other datasets presented in the article and are available from the corresponding author upon reasonable request.

\section{Ethics approval and consent to participate}

Not applicable.

\section{Consent for publication}

Not applicable.

\section{Competing interests}

The authors declare that they have no competing interests.

\section{Author details}

${ }^{1}$ School of Chemical Engineering, Inner Mongolia University of Technology, Hohhot 010051, Inner Mongolia, China. ${ }^{2}$ State Key Laboratory of Microbial Technology, Shandong University, Qingdao 266237, China. ${ }^{3}$ Inner Mongolia Energy Conservation and Emission Reduction Engineering Research Center in Fermentation Industry, Hohhot 010051, China.

Received: 9 March 2019 Accepted: 22 August 2019

Published online: 27 August 2019

\section{References}

1. Ecem Oner B, Akyol C, Bozan M, Ince O, Aydin S, Ince B. Bioaugmentation with Clostridium thermocellum to enhance the anaerobic biodegradation of lignocellulosic agricultural residues. Bioresour Technol. 2018;249:620-5.

2. Zeng $R$, Hu Q, Yin XY, Huang $H$, Yan JB, Gong ZW, Yang ZH. Cloning a novel endo-1,4- $\beta$ - $d$-glucanase gene from Trichoderma virens and heterologous expression in E. coli. AMB Express. 2016;6:108.

3. Seneesrisakul K, Guralp SA, Gulari E, Chavadej S. Escherichia coli expressing endoglucanase gene from Thai higher termite bacteria for enzymatic and microbial hydrolysis of cellulosic materials. Electron J Biotechnol. 2017;27:70-9.

4. Yennamalli RM, Rader AJ, Wolt JD, Sen TZ. Thermostability in endoglucanases is fold-specific. BMC Struct Biol. 2011;11:10.

5. Sadhu S, Maiti TK. Cellulase production by bacteria: a review. British Microbiol Res J. 2013:3:235.

6. Maki M, Leung KT, Qin W. The prospects of cellulase-producing bacteria for the bioconversion of lignocellulosic biomass. Int J Biol Sci. 2009;5:500.

7. Gao D, Wang S, Li H, Yu H, Qi Q. Identification of a heterologous cellulase and its $\mathrm{N}$-terminus that can guide recombinant proteins out of Escherichia coli. Microb Cell Factories. 2015;14:49.

8. Gao D, Luan Y, Wang Q, Liang Q, Qi Q. Construction of cellulose-utilizing Escherichia coli based on a secretable cellulase. Microb Cell Factories. 2015;14:159.

9. Pang J, Liu ZY, Hao M, Zhang YF, Qi QS. An isolated cellulolytic Escherichia coli from bovine rumen produces ethanol and hydrogen from corn straw. Biotechnol Biofuels. 2017;10:165.

10. Ahmad I, Rouf SF, Sun L, Cimdins A, Shafeeg S, Le Guyon S, et al. BcsZ inhibits biofilm phenotypes and promotes virulence by blocking cellulose production in Salmonella enterica serovar Typhimurium. Microb Cell Factories. 2016:15:177.

11. Bokranz W, Wang X, Tschape $H$, Romling U. Expression of cellulose and curli fimbriae by Escherichia coli isolated from the gastrointestinal tract. J Med Microbiol. 2005;54:1171-82.

12. Grantcharova N, Peters V, Monteiro C, Zakikhany K, Romling U. Bistable expression of CsgD in biofilm development of Salmonella enterica serovar typhimurium. J Bacteriol. 2010;192:456-66.

13. Mazur O, Zimmer J. Apo- and cellopentaose-bound structures of the bacterial cellulose synthase subunit BcsZ. J Biol Chem. 2011;286:17601-6.

14. Standal R, Iversen TG, Coucheron DH, Fjaervik E, Blatny JM, Valla S. A new gene required for cellulose production and a gene encoding cellulolytic activity in Acetobacter xylinum are colocalized with the bcs operon. J Bacteriol. 1994;176:665-72.

15. Rabinovich ML, Melnick MS, Bolobova AV. The structure and mechanism of action of cellulolytic enzymes. Biochem Mosc. 2002;67:850-71.

16. Park $Y$, Yun $\mathrm{H}$. Cloning of the Escherichia coli endo-1,4-D-glucanase gene and identification of its product. Mol Gen Genet. 1999;261:236-41. 
17. Lin L, Fu C, Huang W. Improving the activity of the endoglucanase, Cel8M from Escherichia coli by error-prone PCR. Enzym Microb Technol. 2016;86:52-8.

18. Gong X, Gruninger RJ, Qi M, Paterson L, Forster RJ, Teather RM, et al. Cloning and identification of novel hydrolase genes from a dairy cow rumen metagenomic library and characterization of a cellulase gene. BMC Res Notes. 2012;5:566.

19. Chang L, Ding M, Bao L, Chen Y, Zhou J, Lu H. Characterization of a bifunctional xylanase/endoglucanase from yak rumen microorganisms. Appl Microbiol Biotechnol. 2011;90:1933-42.

20. Kim JY, Hur SH, Hong JH. Purification and characterization of an alkaline cellulase from a newly isolated alkalophilic Bacillus sp. HSH-810. Biotechnol Lett. 2005;27:313-6.

21. KOO HM. Expression and characterization of CMCax having $\beta-1$, 4endoglucanase activity from Acetobacter xylinum. BMB Rep. 1998;31:53-7.

22. Demain AL, Newcomb M, Wu JH. Cellulase, clostridia, and ethanol. Microbiol Mol Biol Rev. 2005;69:124-54

23. Zhang P, Yuan X, Du Y, Li JJ. Heterologous expression and biochemical characterization of a GHF9 endoglucanase from the termite Reticulitermes speratus in Pichia pastoris. BMC Biotechnol. 2018;18:35.

24. Meleiro LP, Carli S, Fonseca-Maldonado R, da Silva TM, Zimbardi A, Ward RJ, et al. Overexpression of a Cellobiose-glucose-halotolerant endoglucanase from Scytalidium thermophilum. Appl Biochem Biotechnol. 2018;185:316-33.

25. Zhang F, Chen JJ, Ren WZ, Nie GX, Ming H, Tang SK, Li WJ. Cloning, expression and characterization of an alkaline thermostable GH9 endoglucanase from Thermobifida halotolerans YIM 90462 T. Bioresour Technol. 2011;102:10143-6.

26. Dobrev GT, Zhekova BY. Biosynthesis, purification and characterization of endoglucanase from a xylanase producing strain Aspergillus niger B03. Braz J Microbiol. 2012:43:70-7.

27. Duan C, Xian L, Zhao GC, Feng Y, Pang PH, Bai XL, et al. Isolation and partial characterization of novel genes encoding acidic cellulases from metagenomes of buffalo rumens. J Appl Microbiol. 2009;107:246-56.

28. Sriariyanun M, Tantayotai $\mathrm{P}$, Yasurin P, Pornwongthong P, Cheenkachorn $K$. Production, purification and characterization of an ionic liquid tolerant cellulase from Bacillus $s p$. isolated from rice paddy field soil. Electron J Biotechnol. 2016;19:23-8.

29. Zhou X, Kovaleva ES, Wu-Scharf D, Campbell JH, Buchman GW, Boucias DG, et al. Production and characterization of a recombinant beta-1,4endoglucanase (glycohydrolase family 9) from the termite Reticulitermes flavipes. Arch Insect Biochem Physiol. 2010;74:147-62.

30. Cano-Ramirez C, Santiago-Hernandez A, Rivera-Orduna FN, Garcia-Huante Y, Zuniga G, Hidalgo-Lara ME. Expression, purification and characterization of an endoglucanase from Serratia proteamaculans CDBB-1961, isolated from the gut of Dendroctonus adjunctus (Coleoptera: Scolytinae). AMB Express. 2016;6:63.

31. Irwin D, Shin D-H, Zhang S, Barr BK, Sakon J, Karplus PA, et al. Roles of the catalytic domain and two cellulose binding domains of Thermomonospora fusca E4 in cellulose hydrolysis. J Bacteriol. 1998;180:1709-14.

32. Zhang F, Anasontzis GE, Labourel A, Champion C, Haon M, Kemppainen M, et al. The ectomycorrhizal basidiomycete Laccaria bicolor releases a secreted beta-1,4 endoglucanase that plays a key role in symbiosis development. New Phytol. 2018;220:1309-21.

33. Boyce A, Walsh G. Expression and characterisation of a thermophilic endo1,4-beta-glucanase from Sulfolobus shibatae of potential industrial application. Mol Biol Rep. 2018;45:2201-11.

34. Wu B, Zheng S, Pedroso MM, Guddat LW, Chang S, He B, et al. Processivity and enzymatic mechanism of a multifunctional family 5 endoglucanase from Bacillus subtilis BS-5 with potential applications in the saccharification of cellulosic substrates. Biotechnol Biofuels. 2018;11:20.

35. Sambrook J, Fritsch EF, Maniatis T. Molecular cloning: a laboratory manual. CSH. 1989.

36. Miller GL. Use of dinitrosalicylic acid reagent for determination of reducing sugar. Anal Chem. 1959;31:426-8.

37. Bradford MM. A rapid and sensitive method for the quantitation of microgram quantities of protein utilizing the principle of protein-dye binding. Anal Biochem. 1976;72:248-54.

38. Zhang C, Wang Y, Li Z, Zhou X, Zhang W, Zhao Y, et al. Characterization of a multi-function processive endoglucanase CHU_2103 from Cytophaga hutchinsonii. Appl Microbiol Biotechnol. 2014;98:6679-87.

\section{Publisher's Note}

Springer Nature remains neutral with regard to jurisdictional claims in published maps and institutional affiliations.

\section{Ready to submit your research? Choose BMC and benefit from}

- fast, convenient online submission

- thorough peer review by experienced researchers in your field

- rapid publication on acceptance

- support for research data, including large and complex data types

- gold Open Access which fosters wider collaboration and increased citations

- maximum visibility for your research: over $100 \mathrm{M}$ website views per year

At $\mathrm{BMC}$, research is always in progress.

Learn more biomedcentral.com/submissions 